\title{
ASPECTS REGARDING THE PARTICULARITIES OF THE MILITARY ACTIONS IN THE WAR OF THE FUTURE
}

\author{
Daniel SOLESCU \\ “Nicolae Bălcescu" Land Forces Academy, Sibiu, Romania \\ danielsolescu@yahoo.com
}

\begin{abstract}
The topic "the War of the Future" is and will always be a current issue of high relevance for both military staff and politicians. The war is a complex social phenomenon determined by many factors: political, economic, cultural, religious, technological, etc., which in the context of globalization suffer rapid and profound transformations. Due to changes in these factors, everything that is related to the armed forces is inevitably altered and here we refer to: dimensions, structures, training, equipment and weapons, doctrines, organizing, planning and the spatial and temporal magnitude of military actions and operations, their effects and, of course, consequences.
\end{abstract}

Keywords: war, military actions, training

\section{INTRODUCTION}

War is a complex social phenomenon that depends on the social essence of confrontation. Because of this, war has always been investigated and studied by philosophers and soldiers: some have studied war to discover its causes, physiognomy and philosophy, and to eradicate them, in an attempt to prevent this negative phenomenon; others have sought to understand its mechanisms in order to win.

People and human entities have a lot to share: resources, territories, mentalities, influences and, above all, power. Power is the essential and constant reason for the armed conflict.

Just like any other social phenomenon of great magnitude, war evolves to dimensions, configurations and expressions that are not and cannot be fully known and modeled. That is why the knowledge of the war, especially of the new war, i.e. the war or wars of the 4th and 5th generation, remains one of the great challenges of the present and of the future.
The unpredictable international security situation leads us to the conclusion that we are at a crossroads in what concerns the development of the theory and practice of military confrontation. The objective of this scientific approach is to contribute to the analysis of all forms of war, specific to the fourth generation and especially to the hybrid warfare, which will provide a solid theoretical support necessary for the development of a strategic culture and, consequently, of a corresponding military strategy.

\section{MODERN AND CONTEMPORAY WARS}

The conflict between large groups of people, states, nations, or newer civilizations is a phenomenon that has always impacted on the evolution of mankind, and which has been explained over time in the most diverse ways, being attributed multiple ways of manifestation.

Even though war is still understood today by Clausewitz's definition as " $a$ continuation of politics by other means" 
[1], we consider that it is rather a result of the absence of political power able to manage and control this predisposition of mankind to conflict. Clausewitz's triad science, will, power - is a synthesis of the Cartesian and Hegelian philosophy and will dominate the art of war of all times. These three principles of human action - to know, to want, to be able to - will always govern war at all its stages, not just the conflict [2]. The specialized literature - author works, dictionaries or lexicons, as well as doctrines, regulations and combat manuals - emphasizes the preoccupations of civilian and military theorists for defining and substantiating the dimensions of the war.

In an attempt to define it, it is appreciated that war is the sharpest manifestation of conflicting political relations existing at a given moment between large militarily organized groups of people (classes, peoples, nations, states, state coalitions) and which use violent means to achieve certain economic and political purposes, which gives this phenomenon a powerful destructive character [3].

Modern war does not change the concept of war. It only changes forces, means and actions, depending on the political decision, the limits of engagement and the characteristics of the strategic environment.

For an easier analysis and description of interhuman conflicts, William Lind [4] launched in the late 1980s the idea of a periodization of modern-day conflicts. Described as "generations", this type of division is proposed according to weapon technology and the evolution of war tactics, as follows:

First-generation warfare (1GW) is characterized by the presence on the battlefield of large masses of soldiers (trained, equipped and endowed according to the planned missions), which culminated in the Napoleonic wars. The order of rows and columns on the battlefield generated the specific features that distinguish the civilians from the military: uniform, greeting, ranks, the culture of discipline. If the armies of the past were composed of foreign mercenaries who could hardly wait to desert, the preset notion of being a citizen who fights for their country and people has become an honor.

Second-generation warfare (2GW) appeared after 1860 and World War I is the corollary of this stage. Order on the battlefield was preserved and even strengthened, and the use of the means of fire was carefully planned. A new concept appeared which was encapsulated by the French in the phrase: "The Artillery conquers, the infantry occupies."

Third-generation warfare (3GW) is defined by refining tanks and planes, which has led to improved mobility of forces and increased importance of maneuver in the combat area, across the entire spectrum of military action. Theorists believe that Second World War Blitzkrieg marked the beginning of this generation [5]. The result counts, it is required and expected from the military, but they do not receive the method to obtain it, while the most important thing for the commanders is having initiative.

Fourth-generation warfare (4GW) evolved during the Cold War between the two military blocs, NATO and the Warsaw Treaty respectively, when ideological, political, military, social and economic rivalries led to the emergence of unconventional forms of combat, against an ideological adversary, considered a force difficult to successfully defeat with military means alone. The two military blocs waged their disputes through intermediaries and avoided direct confrontation, as to avoid an escalation of the situation and the use of weapons of mass destruction.

In the events that followed the fall of the Iron Curtain, ethnic, religious and cultural conflicts involved larger groups of people, more or less endowed with military technology and equipment, but much more creative and inventive in using ultramodern technology at their disposal. This has led to the loss of the monopoly of violence by states and the emergence of the hybrid war. A synthetic definition of the hybrid war was formulated by F. Hoffman in 2009. The 
theorist highlighted the nature of this typology as “(...) incorporating a range of different modes of warfare, including conventional capabilities, atypical tactics and formations, terrorist acts, with the inclusion of unrestrained coercion and violence and criminal disorder"'[6].

Hybrid war is a combination of conventional and unconventional regular and irregular, economic, energetic, and cybernetic warfare, combined in a complicated and unstable manner, an unlimited, unrestricted war which allows the development of different capabilities, without rules, which combines criminal aptitudes with economic and informational abilities, propaganda and irregular warfare led by intermediaries, insurrection and terrorism, all in the same theater, where, according to Machiavelli's concept: "The

\section{end justifies the means!"}

This kind of unrestricted war "ignores and transcends the boundaries of the battlefield and of what is not considered battlefield, between what a weapon is and what it is not, between military personnel and civilians, between state and non-state actors"[7], with the ultimate aim of ensuring equal opportunities for the weakest parties in a conflict.

In this context, the hybrid war questions issues related to international humanitarian law and the viability of the modern military engagement rules.

\section{FIFTH-GENERATION WARFARE}

The future competition for resources water, energy, commodities and food - is a major source of conflict. The existential character of the survival of a state depending on these basic resources will increase the choice of violence and the probability of regional instability. Climate change and natural disasters are also destabilizing phenomena. Both exacerbate infrastructure vulnerabilities in many developing countries and increase the likelihood of humanitarian crises, the potential of epidemic diseases and the outlook for population migration at regional level.

Post-modern warfare encompasses all possible forms - symmetrical, dissymmetrical and asymmetrical - and is not limited to conflict but, on the contrary, amplifies it [8].

Symmetrical confrontation consists in the action of two similar (but not identical) armed entities in terms of their organization, physiognomy, doctrine and mode of action, and the surprise is achieved mainly through the use of information and the originality of operational strategies.

Dissymmetrical confrontation is a confrontation between two or more entities, disproportionate and distinct from each other, in terms of potential, doctrine and technology, as well as in what regards their organization, endowment, and mode of action.

Asymmetrical confrontation is an accentuated reality of the modern age, due to the vulnerabilities and threats that are a product of huge technological gaps, of the state of chaos generated by the competition for resources and of the reconfiguration of power centers.

At the tactical level, the basic principles of 5GW are:

- missions and operations are performed by small, highly armed sub-units of combatants who can easily act in areas of interest;

- the subunits have a high-autonomy combat capacity without being dependent on centralized logistics;

- combat subunits are agile with a high level of mobility during day and night, and maneuverability ensures their superiority on the ground;

- combat actions aim to destroy the enemy from within and focuses on its power centers.

Opposing forces can also be transnational groups with mobile territorial bases that do not act with predefined subunits. Forms and methods of combat are borrowed and perfected from the guerilla war panoply, and are based on terrorist actions or lowintensity conflicts. These forces can 
perform tactical missions with strategic impact, and their military capability does not coincide with the value of the targets.

A significant part of the opponents does not wear uniforms, distinctive signs or visible guns, which makes it hard to distinguish between civilians and soldiers. The clashes between combatants are sporadic, sometimes dangerous, and are carried out in the presence and at the cost of civilians' lives.

In a global environment typified by rapid technological, societal and demographic changes, international security is provoked by an increasingly belligerent Russia and by the rise of China's economic and military power.

In order to meet future challenges, the North Atlantic Treaty Organization (NATO) needs to adapt quickly; through the acquisition or production of new military technologies and by training future leaders who can act on the future nonlinear battlefields without reliable communications but who are capable of making wise and ethical decisions.

Part of the upcoming challenge is that while the United States and other NATO member states have focused on combating terrorism and counterinsurgency, other nations "went to school" and studied the doctrine, organization, leadership, tactics, equipment and the mode of action of the opponents and also revised their own doctrines while rapidly modernizing their capabilities.

Land-based military actions are on the verge of fundamental changes. The nature of these actions - how and where the combat takes places and with what weapons and tactics - will undergo radical, profound and meaningful changes. The main trends in the evolution of military actions will be:

- Emphasis on the expeditionary nature of military actions, as more and more states will have interests and forces capable of carrying out actions at great distances;

- Military actions will have a joint character, obtained by mixing the actions of the four components - land, air, naval and cosmic.

Expanding the sphere of participating forces to accomplish the same mission - interagency actions, due to the specificity of the struggle and complexity of the operational environment.

- Increased precision in target selection and neutralization due to highprecision weapons and intelligent ammunition used with deep psychological effects on the opponent.

NATO forces must be prepared to engage in cyber wars, and able to fight in a complex urban setting. It will be difficult for military formations to hide in sensorflooded battlefields, which means that survival may depend on having smaller and more mobile forces, while military actions will move into dense, multi-weapon and robotic urban areas with a large civilian population in the midst of the combat, a situation which makes the enemy evasive and combines conventional war with terrorism and guerrilla activities. This requires significant changes in the current methods of thinking, training and combat. "Army operations in complex and densely populated urban areas are the toughest and most bloody form of combat and, in the future, will become the norm, not the exception" [9].

Land Forces need new capabilities in order to operate in urban fights. Improvements in information and recognition systems are important for identifying targets in a confusing urban context, and forces will need to be able to operate independently for long periods of time and will require longrange precision weapons.

The army will have to strengthen its electronic systems so as to defend itself against cyber- attacks and electronic warfare and must be prepared to operate without satellite-based communications and navigation. "The ability of the units to produce or purify their own water and to manufacture their own spare parts with $3 D$ printing might become a necessity" [10]. The power lines might have to be largely based on autonomous systems, such as robots and remotely controlled convoys, to reduce the risk of life losses. 
In the short run, the army must focus on improving the existing critical capabilities. Critical capabilities include lethality, protection, integrated airspace defense, ground mobility and, above all, the improvement of the mission command network. Both the offensive and the defensive cyber capabilities will have a massive impact on military actions.

Modern armies are making serious efforts to modernize the "Third Millennium Fighter", because military specialists take into account that one of the main success factors in the armed combat of the future warfare is to provide increased capabilities to the fighter, considered to be the fundamental entity of the whole system.

All soldier systems that are currently under study - Land Warrior (USA), FIST (GB), FELLIN (F) etc., will be operationalized and adapted to the new battlefield. The soldier system is a fully integrated individual combat system, endowed with a large destruction capacity, including various weapons, network communications, energy sources, and increased body integrity.

Due to the confrontational environment, future wars could exclude the comfort and stability of a well-equipped base from the life of the soldiers, while the combat and living will occur under extremely austere conditions. The lack of food, water, or sleep will have major repercussions on the physical and mental health of the military.

Soldiers will also need to be more independent and more imaginative, and that may also mean being able to selectively abide by orders in circumstances when they are in direct contact with their superiors.

We should take into account the fact that the forms of manifestation of military actions, their preparation and organization, as well as the manner of conducting warfare will undergo radical changes. Soldier systems and their subunits might be removed from combat by opposing forces, even if they are less endowed and less equipped with sophisticated military equipment and technique, but might know and use the land and the neuralgic points in the action area more skillfully.

The presence at the right time and place, the exploitation of the adversary's weakness, the ambushes and the short-term violent attacks, based on the "hit and run" principle, resulting in as many victims as possible generated by the dissipation of the opponents among the civilian population, the threats by vectors with the "imminence" of a bloody attack to create a permanent state of insecurity supplemented by various IEDs, the abductions of soldiers or civilians etc., are just a few of the combat methods of the opposition forces. The strategy of the adversaries is not to win the battle; it is war itself. They will not seek to take the military forces out of the battle, and will even avoid direct engagement. All their actions will focus on destroying the opponent's political will.

\section{CONCLUSIONS}

One of the most prominent global trends is the advancement of economic globalization, but above all, the globalization technology, which has led to increased global connectivity and knowledge of scientific advances, trends that bring prosperity to the world, but which also highlight discrepancies in wealth and power between countries or citizens. These two phenomena of the 21st century are working in tandem and, because of the lack of vigilance of the political factors, have provided the means for exporting terrorism and extremism to the whole world.

In addition, more cultures have experienced an increase in radicalism, and those who feel victimized or threatened by globalization have become more and more attracted to extremist religious groups. With more and more followers, the conceptions, motivations and activities of radical groups, especially the religious ones, are difficult to moderate and often intensify and prolong a conflict.

The new nature of warfare does not consist merely in the form and content of the armed conflict, in the more or less classical configurations and more or less modern 
confrontations in the theaters of operations or in the theaters of war, but in the purposes, objectives and especially in the effects of the war.

From a practical point of view, the war of the future involves actions of the great world entities (alliances, coalitions, very strong international communities, groups of states constituted in strategic partnerships etc.) against each other or against dictatorial political regimes, states that shelter or generate terrorism and asymmetric threats. Among the most important principles of the new warfare we consider the following: technological and informational dominance, media extension and indirect actions.

Paraphrasing William Lind, who began his initial research on $4 \mathrm{GW}$ by declaring that "in peacetime, the soldier's main task is to prepare for the next war effectively. To do so, he must anticipate what the next war will be like" [11]. We consider that the task of Military Academies is to prepare military leaders not for the war of tomorrow but for the war of the future. Research centers together with Training Centers have the task to develop specific action models that facilitate the involvement of the armed forces in possible future conflicts, as well as a model of the fighter and the military leader, specific to the next decade.

It is necessary to introduce studies of universal history, anthropology, economics, geopolitics, culture, law and strategic communications in the training of military leaders. Simultaneously with the expansion of their intellectual horizons, future military leaders must understand the nature of future conflicts and refine their ability to think critically and creatively about the acquisition and allocation of human and material resources in the operation areas.

At the same time, it is essential to reconfigure the organization, endowment, and especially the training of the armed forces for future fights and battles. On the one hand, the military should accelerate the increase of its special forces (land, sea and air) and, on the other hand, it needs to turn its regular forces into more agile, "multipurpose" forces with great flexibility on the battlefield, that are more credible and powerful, capable of performing conventional and unconventional actions, and to carry out stability and support missions. These forces must be capable of operating independently with or without the support of senior echelons or civilian agencies.

\section{References}

[1] CLAUSEWITZ, von Carl, Despre război, Editura Militară, Bucureşti, 1982, p. 67;

[2] MUREŞAN Mircea, VĂDUVA Gheorghe, Războiul viitorului, viitorul războiului - Ed. a 2-a - Bucureşti: Editura Universităţii Naţionale de Apărare „Carol I“, 2006, p.66;

[3] ***, Doctrină şi teorie militară, Editura Militară, Bucureşti, 1987, p. 306;

[4] William S. Lind, Keith Nightengale, John F. Schmidt, Joseph Sutton, and Gary I. Wilson The Changing Face of War: Into the Fourth Generation. Marine Corps Gazette (October 1989);

[5] HAMMES, Thomas X., 4th-generation Warfare: Our Enemies Play to Their Strenghts, in Armed Forces Journal, November 2004, pp. 40-44; http://www.d-ni.net/second level/fourth generation warfare.htm.

[6] HOFFMAN, Frank, G., Hybrid vs. Compound War. The Janus choice: Defining today's multifaced conflict, Armed Forces Journal, October 2009

[7] Steve Metz, Strategic Horizons: In Ukraine, Russia Reveals Its Mastery of Unrestricted Warfare, World Politics Review, 16 aprilie 2014

[8] VĂDUVA, Gheorghe, Război şi cunoaştere, Editura Universităţii Naţionale de Apărare „Carol I” București, 2008, p.40;

[9] Gl. Mark Milley, Association of the U.S. Army 2017 Annual Meeting and Exposition;

[10] Idem;

[11] William S. Lind, Keith Nightengale, John F. Schmidt, Joseph Sutton, and Gary I. Wilson, Op.cit., p. 22. 